\title{
Morphological study of boar sperm during their passage through the female genital tract
}

\section{Francisco Alberto GARCÍA-VÁZQUEZ1, 4), Iván HERNÁNDEZ-CARAVACA', 2), Carmen MATÁS1, 4), Cristina SORIANO-ÚBEDA ${ }^{1,4)}$, Silvia ABRIL-SÁNCHEZ ${ }^{1)}$ and María José IZQUIERDO-RICO ${ }^{3,4)}$}

\author{
1) Department of Physiology, Faculty of Veterinary Science, International Excellence Campus for Higher Education and \\ Research "Campus Mare Nostrum", University of Murcia, Murcia 30100, Spain \\ ${ }^{2)}$ Boehringer-Ingelheim S.A., Barcelona 08173, Spain \\ ${ }^{3)}$ Department of Cell Biology and Histology, Faculty of Medicine, International Excellence Campus for Higher Education \\ and Research "Campus Mare Nostrum," University of Murcia, Murcia 30100, Spain \\ 4) Institute for Biomedical Research of Murcia (IMIB-Arrixaca), Murcia, Spain
}

\begin{abstract}
Once deposited in the female tract, sperm face a series of challenges that must be overcome to ensure the presence of an adequate normal sperm population close to the site of fertilization. Our aim was to evaluate the influence of the uterine milieu on boar sperm morphology. In experiment 1, sperm morphology was evaluated in the backflow (60 min after insemination) and within the uterotubal junction (UTJ) (collected $\sim 24 \mathrm{~h}$ after insemination) following intrauterine sperm deposition $(n=6)$ and compared with the morphology of the sperm in the insemination dose. In experiment 2, the influence of the uterine fluid (UF) on sperm morphological modifications was evaluated. For this purpose, ejaculated $(\mathrm{n}=4)$ and epididymal $(\mathrm{n}=4)$ sperm were in vitro incubated with or without UF for 2 and $24 \mathrm{~h}$. In both experiments, sperm were classified as normal, having a cytoplasmic droplet (proximal or distal) or having tail defects. The results of experiment 1 pointed to an increase in morphologically abnormal sperm collected in the backflow $(27.70 \%)$ and a reduction of the same in the UTJ $(2.12 \%)$ compared with the insemination dose $(17.75 \%)(\mathrm{P}<0.05)$. In experiment 2 , incubation of ejaculated sperm with UF did not provoke any morphological modifications; however, when epididymal sperm were incubated with UF, a pronounced increase in the percentage of normal sperm was evident after $24 \mathrm{~h}$ compared with the initial dose (from $25.77 \%$ to $53.58 \%, \mathrm{P}<0.05)$, mainly due to distal cytoplasmatic droplet shedding (53.22 vs. 20.20\%). In conclusion, almost all the sperm that colonize the UTJ had a normal morphology, with part of the abnormal sperm having been discarded in the backflow and part selected/modified on their way to the oviduct. UF seems to influence cytoplasmic distal droplet removal, as demonstrated previously in seminal plasma.
\end{abstract}

Key words: Backflow, Cytoplasmic droplet, Porcine, Sperm morphology, Uterine fluid

(J. Reprod. Dev. 61: 407-413, 2015)

$\mathbf{H}$ ow and why some specific sperm rather than others reach the oocyte within the uterus is not clear. From the billions of sperm inseminated only thousands reach the uterotubal junction (UTJ) and caudal isthmus [1,2], where they establish the sperm reservoir. The influx of polymorphonuclear neutrophils (PMNs) and retrograde flow (backflow) after insemination are two of the main known mechanisms by which sperm are cleansed from the genital tract, as reviewed by Soriano-Úbeda et al. [3]. Although it is not clear how sperm are selected, what seems evident is that the female reproductive system and the properties of the sperm themselves are involved in the natural process of sperm selection on their way to the fertilization site [4].

Once the spermatozoa are deposited in the female genital tract,

Received: December 24, 2014

Accepted: May 22, 2015

Published online in J-STAGE: June 26, 2015

(C)2015 by the Society for Reproduction and Development

Correspondence: FA García-Vázquez (e-mail: fagarcia@um.es)

This is an open-access article distributed under the terms of the Creative Commons Attribution Non-Commercial No Derivatives (by-nc-nd) License $<\mathrm{http}: / /$ creativecommons.org/licenses/by-nc-nd/3.0/>. they still have to overcome several obstacles (e.g., the cervix) and different environments (e.g., uterine and oviductal fluid) that may have a detrimental effect on sperm populations $[5,6]$. In an experiment in pigs, only $10 \%$ of the inseminated spermatozoa were recovered from the uterus $2 \mathrm{~h}$ after sperm cervical deposition [7], reflecting the difficulties involved in crossing the cervix. On the other hand, spermatozoa within an ejaculate are heterogeneous in many aspects, for example, as regards motility, morphology, morphometry, DNA integrity, acrosome status or the efficiency of their signal transduction pathways (e.g., capacitation) $[4,5]$. These observations suggest that spermatozoa within an ejaculate compete with each other and that the capability of the sperm to colonize the oviduct is involved in egg fertilization, although the specific characteristics of the spermatozoa that finally fertilize the oocyte remain unknown.

Identifying which sperm traits influence male fertility is the first step in understanding how selection affects sperm quality [8]. Nowadays, semen assessment methods are commonly used in spermiograms in infertility clinics for humans or AI centers (for livestock species) and have also been used as an indicator of sperm quality, although how fertile a sample really is still cannot be predicted [4]. Sperm morphology is one of the routinely evaluated 
parameters in a sperm sample. Spermatozoa in the epididymis possess a proximal cytoplasmic droplet (behind the neck), which is translocated to a distal position (at the end of the midpiece) during their transit through the epididymis before reaching their final maturation site (cauda epididymis) (reviewed by Cooper [9]). The fact that a low percentage of ejaculated spermatozoa in different species have droplets suggests that they are removed during ejaculation [9]. So, the presence of sperm cytoplasmic droplets (proximal or distal) in an ejaculate has generally been considered to be detrimental to semen storage $[10,11]$ or indicative of reduced potential fertility [12-14], sperm plasma membrane alteration [15] or a reduced ability to interact with porcine oviductal epithelial explants [16]. Moreover, abnormalities in the flagellum disqualify spermatozoa from taking part in fertilization [4].

Although several studies have analyzed sperm morphology within the uterus in a variety of species [17-19], no study has compared sperm morphology in the ejaculate, backflow and uterus at the same time. We hypothesize that sperm of abnormal morphology are naturally discriminated against after deposition and discarded through the backflow or selected or modified within the uterus during their journey to the oviduct. The present study was divided into two experiments. In the first experiment, to evaluate whether the uterus acts as a barrier to abnormal sperm, sperm with an abnormal morphology in the backflow ( 60 min of insemination) and within the UTJ ( $24 \mathrm{~h}$ after insemination) were compared with the semen used for insemination. Post-cervical insemination was used to deposit the sperm directly into the uterus body, thus avoiding the cervix (a known barrier for sperm) to test whether the uterine horns can select normal sperm per se. In the second experiment, which was carried out to evaluate whether the composition of the uterine fluid (UF) could influence sperm morphology (e.g., shedding of cytoplasmic droplets), ejaculated spermatozoa (high percentage of morphologically normal sperm and presence of seminal plasma) and epididymal spermatozoa (low percentage of morphologically normal sperm and no seminal plasma) were incubated with UF for $24 \mathrm{~h}$.

\section{Material and Methods}

\section{Ethics}

This study was carried out in strict accordance with the recommendations in the Guiding Principles for the Care and Use of Animals (DHEW Publication, NIH, 80-23). The protocol was approved by the Ethical Committee for Experimentation with Animals of the University of Murcia, Spain (project number: AGL2012-40180-C03-01). All surgeries were performed following analgesic and anesthetic protocols [20], and efforts were made to minimize suffering.

\section{Spermatozoa collection}

Ejaculates from mature boars (Duroc) of proven fertility were used in this study. The ejaculates were obtained after at least 3-4 days of abstinence. The samples were collected by the gloved-hand technique and filtered to remove the gel. The sperm samples had to fulfill minimal quality criteria before use: rich fraction volume $\geq 75 \mathrm{ml}$, concentration $\geq 200 \times 10^{6} \mathrm{sperm} / \mathrm{ml}$, motility $\geq 70 \%$ and vitality $\geq 85 \%$. When necessary, samples were cooled to $15 \mathrm{C}$ and transported at that temperature to the laboratory for further analysis.
Epididymal spermatozoa were collected as previously described [21]. Briefly, within $30 \mathrm{~min}$ of slaughter, the porcine cauda region of the epididymis was dissected, and the spermatozoa were obtained by retrograde air flushing. For this purpose, a $21-\mathrm{G}$ needle attached to a 5-ml syringe filled with air was introduced into the vas deferens. Spermatozoa were then flushed in a retrograde direction from the vas deferens through the cauda epididymis and collected into a 1.5-ml Eppendorf tube.

\section{Uterine fluid (UF) collection}

Genital tracts from sows (commercial hybrid Landrace $\times$ Large White) were obtained at a slaughterhouse (El Pozo Alimentación S.A., Alhama de Murcia, Murcia, Spain) and transported to the laboratory on ice within $1 \mathrm{~h}$. The stage of the estrus cycle was assessed once in the laboratory according to ovarian morphology. Only the tracts classified as in late follicular phase [periovulatory follicles (8-11 $\mathrm{mm}$ in diameter) or close to ovulation ( $>11 \mathrm{~mm}$ in diameter)] were used to obtain UF $[22,23]$. Once classified, the uterine horns from each sow were separated, and the UF was obtained by mechanical pressure from the cranial to the caudal part of the uterus (oviductuterine body direction). The fluid was centrifuged (7000 $\mathrm{g}$ for 10 min $4 \mathrm{C}$ ) to eliminate cellular debris, and the supernatant was kept at $-20 \mathrm{C}$ until use.

\section{Estrus detection and artificial insemination (AI)}

Multiparous sows (Large white $\times$ Landrace) $(3-5$ parity) used for breeding were weaned 28 days after farrowing. Estrus detection was performed twice daily and defined by the standing reflex in front of a teaser boar and by reddening and swelling of the vulva.

Sows were inseminated with a single dose $\left(1.5 \times 10^{9}\right.$ spermatozoa per dose in $40 \mathrm{ml}$ of extender, Zoosperm ND4, Import-Vet S.A., Barcelona, Spain) $24 \mathrm{~h}$ after oestrus detection. Post-cervical AI was performed using a combined catheter-cannula kit (Soft \& Quick ${ }^{\circledR}$, Import-Vet). Before insemination, the perineal area was carefully cleaned with $0.5 \%$ chlorhexidine gluconate wipes (Despro ${ }$, Import-Vet).

\section{Backflow collection}

After insemination, the perineal area was thoroughly dried. The semen backflow was collected in human colostomy bags (Hollister Ibérica S.A., Madrid, Spain) (fixed around the vulva and secured with tape) over a period of $60 \mathrm{~min}$ following insemination.

\section{Surgeries and sperm recovery}

The inseminated sows were subjected to sedation and anesthesia $\sim 24 \mathrm{~h}$ after AI. Preoperative anesthesia and analgesia was carried out as previously described [20]. The anesthetic level was maintained using isoflurane (Isoflo ${ }^{\circledR}$, Laboratorios Dr. Esteve S.A., Barcelona, Spain) vaporized in oxygen at $2-3 \%$. All of the inseminated sows were ovulated the day of surgery. The genital tract was exposed through a mid-ventral incision (laparotomy). The UTJ segments ( $1 \mathrm{~cm}$ of the tip of the uterine horn and $1 \mathrm{~cm}$ from the oviductal isthmus) were flushed twice with $1 \mathrm{ml}$ of phosphate-buffered saline (PBS) (Sigma-Aldrich ${ }^{\circledR}$, Madrid, Spain). 


\section{Sperm morphology analysis}

Sperm morphology was determined by mixing semen samples in $2 \%$ buffered glutaraldehyde solution, placing $10 \mu 1$ of the fixed solution on glass slides and covering the glass slides with coverslips $(24 \times 24 \mathrm{~mm})$. Spermatozoa were examined under a phase-contrast microscope (Nikon $\AA$, Eclipse E200, Tokyo, Japan) to analyze the morphology under an oil immersion objective $(1000 \times$ magnification $)$. Spermatozoa were classified into one of the following categories (Fig. 1): normal morphology (normal), cells with an attached proximal cytoplasmic droplet (PCD), cells with a distal droplet (DCD) or cells with tail defects (TD) (folded and coiled tails) [24].

\section{Experimental design}

This study was divided into two experiments.

Experiment 1 was designed to evaluate spermatozoa selection within the uterus based on their morphology and avoidance of the cervix barrier (post-cervical insemination). Rich sperm fractions were obtained from fertile boars $(\mathrm{n}=2)$ and diluted in commercial extender $\left(1.5 \times 10^{9}\right.$ spermatozoa $\left./ 40 \mathrm{ml}\right)$. Six multiparous sows were inseminated (distributed three per boar) $24 \mathrm{~h}$ after estrus detection. The morphology of spermatozoa in the inseminated dose, backflow (collected during 60 min post-insemination) and UTJ (collected $\sim 24 \mathrm{~h}$ after insemination) was analyzed and classified as mentioned above (see the sperm morphology analysis section). A total of 2800 spermatozoa were evaluated in this experiment (insemination dose $=800$, backflow $=1000$ and $\mathrm{UTJ}=1000$ ).

Experiment 2 was designed to ascertain whether the UF (mimicking the milieu that spermatozoa find in the uterus) can influence sperm morphology at different times. Four ejaculates and four epididymal sperm samples (from different boars) and a pool of samples of UF in the late follicular phase (from three different females) were used for this experiment. Ejaculated and epididymal spermatozoa morphology (classified as mentioned above) was analyzed in the following experimental groups: 1) ejaculated or epididymal sperm (initial samples), spermatozoa morphology in the samples before incubation; 2) control $2 \mathrm{~h}$, sperm incubated for $2 \mathrm{~h}$ at $38 \mathrm{C} ; 3$ ) control $24 \mathrm{~h}$, sperm incubated for $24 \mathrm{~h}$ at $38 \mathrm{C}$; 4) UF $2 \mathrm{~h}$, sperm incubated with $20 \% \mathrm{UF}$ for $2 \mathrm{~h}$ at $38 \mathrm{C}$; and 5) UF $24 \mathrm{~h}$, sperm incubated with $20 \%$ UF for $24 \mathrm{~h}$ at $38 \mathrm{C}$. Groups were adjusted in PBS to reach a final concentration of $40 \times 10^{6} \mathrm{sperm} / \mathrm{ml}$. For each group and type of sperm (ejaculated and epididymal), 1200 sperm were examined. A total of 4 replicates were performed.

\section{Statistical analysis}

Statistical analyses were performed using SPSS v.15 (SPSS, Chicago, IL, USA). Data are expressed as the mean \pm SEM and were analyzed by one-way ANOVA. When ANOVA revealed a significant effect, values were compared using the least significant difference pairwise multiple comparison post hoc test (Tukey). Differences were considered statistically significant at $\mathrm{P}<0.05$.

\section{Results}

\section{Experiment 1}

Before insemination, the morphology of the ejaculated sperm (initial sample) was analyzed and found to be $82.25 \%( \pm 2.41)$
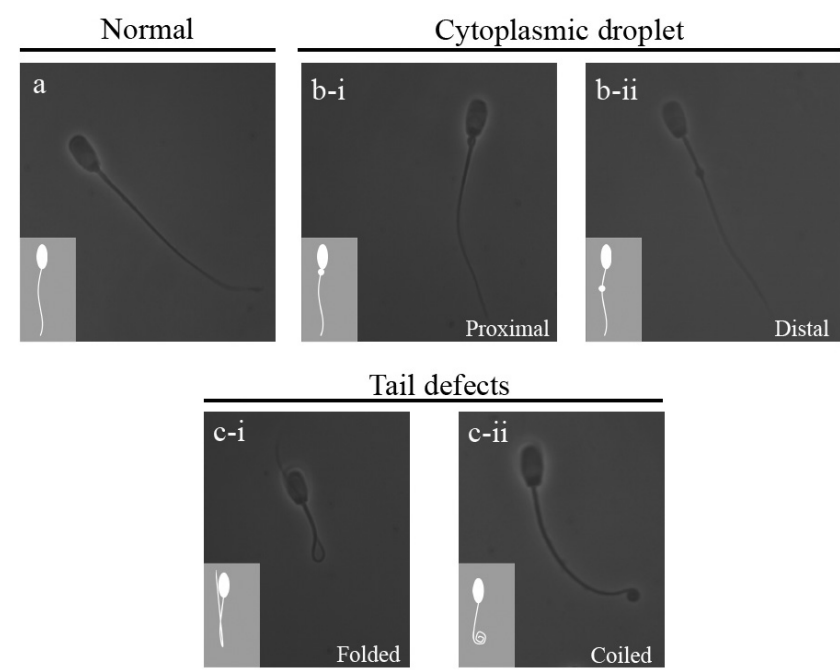

Tail defects

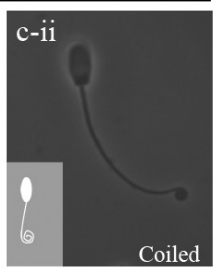

Fig. 1. Classification of sperm morphology: a) normal sperm, b) sperm with an attached proximal (b-i) or distal (b-ii) cytoplasmic droplet, c) sperm with tail defects (c-i, folded tail; c-ii, coiled tail).

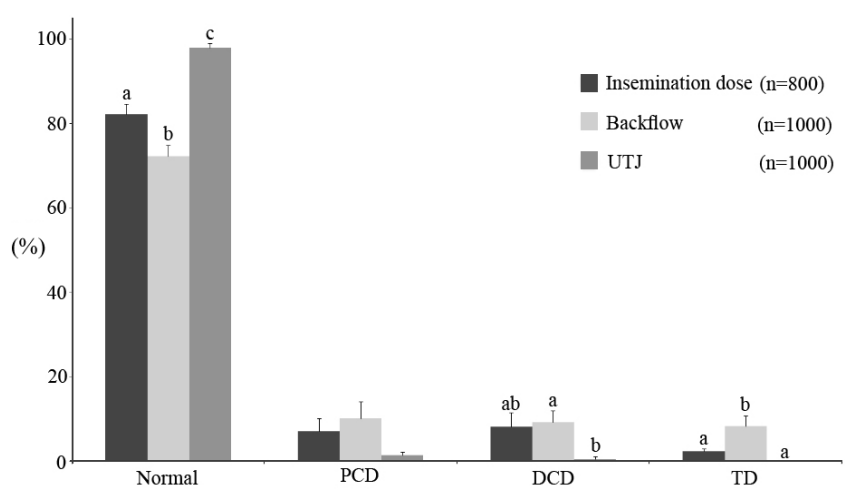

Fig. 2. Sperm morphology in the insemination dose compared with sperm in the backflow and within the uterus (UTJ). Data expressed as the mean \pm SEM. Letters $(a, b, c)$ next to each morphological classification indicate significant differences $(\mathrm{P}<0.05)$.

normal sperm, $15.37 \%$ sperm with cytoplasmic droplets (PCD, $7.12 \pm 3.15 ; \mathrm{DCD}, 8.25 \pm 3.26 \%)$ and $2.37 \%( \pm 0.59)$ sperm with TD (Fig. 2). Backflow was collected in colostomy bags during the 60 min following insemination: $72.30 \%( \pm 2.35)$ of the sperm had a normal morphology, indicating an increase of $\sim 10 \%$ in abnormal sperm compared with the insemination dose $(\mathrm{P}<0.05)$. An increase in TD was observed in the backflow $(8.30 \pm 2.51 \%)$ compared with the insemination dose $(2.37 \pm 0.59 \%)$ (Fig. $2 ; \mathrm{P}<0.05)$. On the other hand, almost all of the sperm obtained from the UTJ had a normal morphology $(97.88 \pm 1.09 \%)$ (Fig. 2), which means an increase of $\sim 15 \%$ compared with the insemination dose $(\mathrm{P}<0.05)$. No TD were observed in sperm collected from the UTJ. Moreover, no differences were found in the morphology of sperm collected from the right and left UTJs (Fig. 3). 


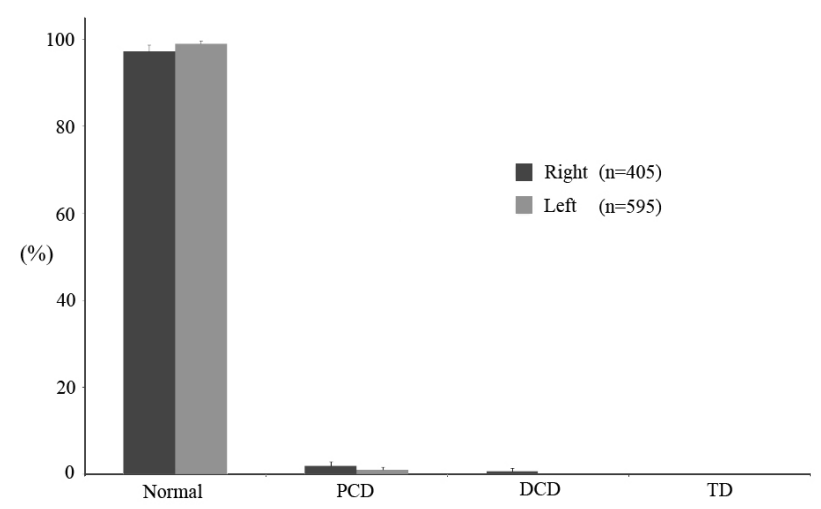

Fig. 3. Comparison of sperm morphology in sperm collected from the right and left UTJs. Data expressed as the mean \pm SEM.

\section{Experiment 2}

The results for ejaculated sperm are shown in Fig. 4. No differences were found in sperm morphology among the different experimental groups $(\mathrm{P}>0.05)$ for any of the parameters studied (normal, 70.25-75.58\%; PCD, 2.58-4.62\%; DCD, 17.67-24.06\%; TD, 1.50-3.67\%). As regards epididymal sperm (Fig. 5), the percentage of morphologically normal sperm in the initial samples was $25.77 \%( \pm$ 4.88), but $24 \mathrm{~h}$ after incubation in UF, the normal sperm morphology increased to $53.58 \%( \pm 5.91)(\mathrm{P}<0.05)$. This was mainly due to the decrease in DCD, from $53.22 \%$ in the initial samples to $20.20 \%$ in the UF for 24 h group $(\mathrm{P}<0.05)$. The decrease in DCD started to be significant $(\mathrm{P}<0.05)$ with respect to the initial sample $2 \mathrm{~h}$ after incubation in UF $(27.66 \pm 1.92 \%)$. No differences were observed in the percentages of PCD (range 19.62 to $22.77 \%$ ) and TD (range 1.29 to $4.62 \%$ ) when the 5 experimental groups were compared.

\section{Discussion}

Why one sperm should be more capable of fertilizing oocytes than millions of others deposited in the female genital tract is still controversial. The uterus represents a foreign environment for spermatozoa, which come up against several barriers and possible setbacks during their journey to the oviduct before they can be selected at the site of fertilization. The results of this study indicate (see Fig. 6), that the uterus acts as a barrier to abnormal sperm, which are collected into the backflow; that during their journey through the female reproductive tract, almost $100 \%$ of sperm that colonize the UTJ have a normal morphology; and that the UF does not seem to be involved in cytoplasmic droplet shedding during the transport of ejaculated sperm to the oviduct, although the presence of UF influences distal droplet removal in epididymal sperm.

The backflow of semen is a physiological process in pigs, since it happens after both natural [25] and artificial [26, 27] insemination and occurs in almost $100 \%$ of females [28]. When AI is performed, approximately $15-25 \%$ of the total sperm deposited in the uterus are refluxed within $60 \mathrm{~min}$ of AI [29]. The results in the present study point to an increase in the percentage of morphologically abnormal sperm collected in the backflow compared with those initially

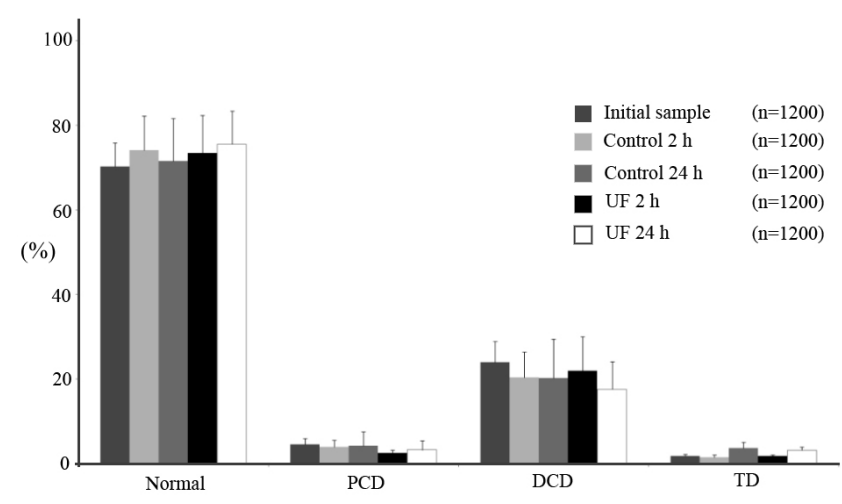

Fig. 4. Morphology of ejaculated spermatozoa (mean \pm SEM) incubated with (UF group) or without uterine fluid (control group) for 2 and $24 \mathrm{~h}$ at $38 \mathrm{C}$. The initial sample group corresponds to the morphology of spermatozoa after ejaculation but prior to incubation.

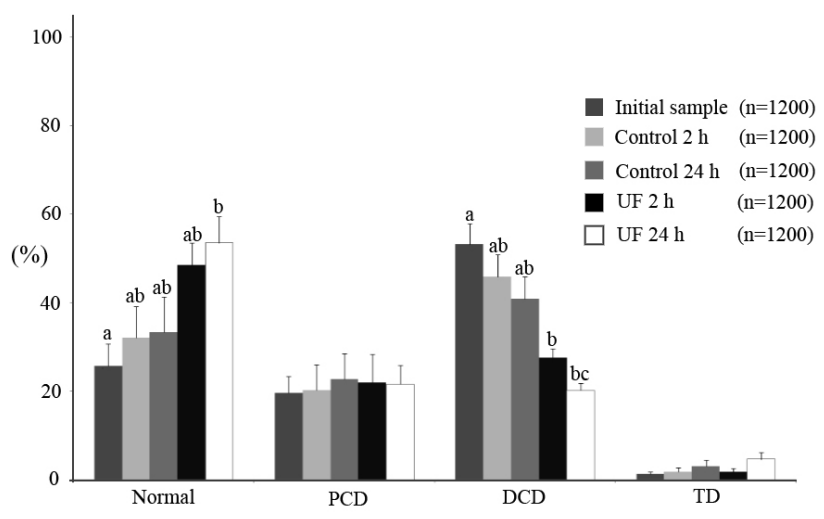

Fig. 5. Morphology of epididymal spermatozoa (mean \pm SEM) incubated with (UF group) or without uterine fluid (control group) for 2 and $24 \mathrm{~h}$ at $38 \mathrm{C}$. The initial sample group corresponds to spermatozoa obtained from the epididymis prior to incubation. Letters $(a, b, c)$ next to each morphological classification indicate significant differences $(\mathrm{P}<0.05)$.

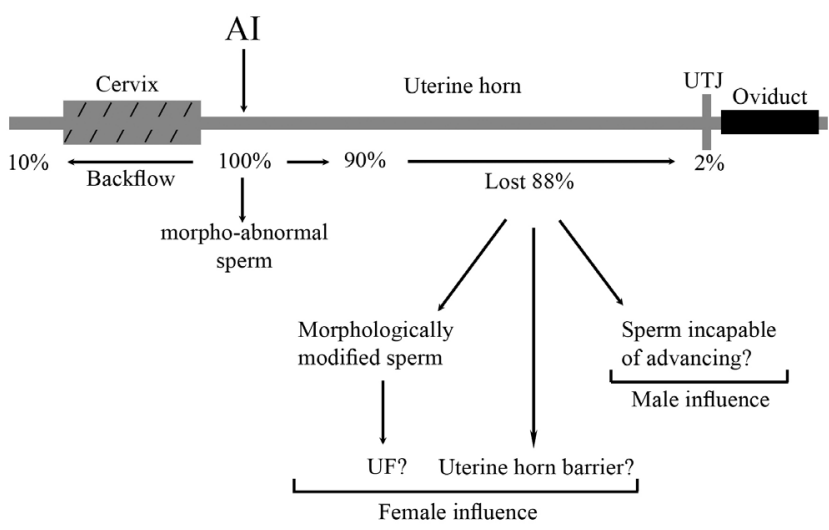

Fig. 6. Representation of morphologically abnormal sperm within the female genital tract (based on the data from the present study) after intrauterine deposition. The total amount of morphologically abnormal sperm deposited is indicated as $100 \%$. 
deposited in the uterus body. Previously, it has been suggested that a first selection based on sperm morphology takes place in the cervix, as in humans [19]. In our case, insemination was performed into the uterine body, but the percentage of morphologically abnormal sperm collected in the backflow was higher compared with the insemination dose. This data suggests that, in addition to the cervix, the uterine horns take part in sperm selection.

Following their journey, the remaining sperm cells continue their search for the oocyte in the female tract. As mentioned in the results, almost $100 \%$ of the sperm reaching the UTJ had a normal morphology. Two explanations (see Fig. 6) may be proposed for these findings: 1) the uterus acts as sperm selector based on sperm morphology (experiment 1) and/or 2) the environment within the uterus (e.g., UF components) promotes the shedding of cytoplasmic droplets (experiment 2).

In agreement with our results, Mortimer et al. [18] found $<1 \%$ of abnormal human sperm in oviducts compared with $\sim 18 \%$ in the inseminated sperm; furthermore, the sperm recovered from the murine uterus after mating also displayed no cytoplasmic droplets [17]. It is widely believed that selection of viable spermatozoa occurs during their passage through the lower parts of the female tract and through the UTJ $[1,30]$. Our results indicate that $\sim 98 \%$ of sperm that colonize the UTJ have a normal morphology.

The female reproductive tract may employ molecular recognition mechanisms to obtain information about individual spermatozoa, implying communication between the two [31]; in this way, females would choose the spermatozoa able to reach and fertilize the oocyte [8]. The female reproductive tract may be able to reject membrane-damaged spermatozoa [31,32], discriminating between the cells based on DNA integrity. Furthermore, evaluation at high magnification revealed that poor human sperm morphology [33] was correlated with sperm carrying fragmented DNA. In our study, the results concerning the proportion of sperm with normal morphology suggest that sperm selection in the uterus horn could be related to DNA status. Moreover, a negative sperm surface charge seems to be involved in sperm quality and to be related to sperm maturation. An increased sperm surface negative charge is correlated with sperm maturation, and the uterus acts to filter out immature sperm [31].

Part of the sperm population is phagocytosed by PMNs after insemination. It has been hypothesized that aged or dead sperm bind to PMNs [34-36] during their journey within the uterus, although other authors [37] showed in an ex vivo experiment that PMNs are attached mainly to viable sperm. The correlation between PMNs and morphologically abnormal sperm attachment has not been demonstrated, suggesting the existence of a female mechanism to reduce the proportion of this type of sperm within the uterus, thus preventing them from reaching the oviduct.

Essentially, morphologically normal sperm have a greater capacity to bind to the oviduct, suggesting a selective process $[16,38]$. In addition, ejaculated spermatozoa with cytoplasmic droplets may be altered in the carbohydrate-binding sites, reducing their capacity to adhere to epithelial cells in the oviduct [38], as in the case of sperm tails with hairpin loops [32]. In the same way, sperm are also attached to uterine epithelial cells [37], and, as occurs in the oviduct, sperm with a normal morphology may be bound to the uterus, while a higher proportion of abnormal sperm cells may be expelled in the backflow than attached sperm, i.e., sperm with normal morphology. Moreover, sperm with proximal cytoplasmic droplets have a low fertility potential under in vitro conditions in species such as the human [39], bovine [12, 13] or canine [14], which exhibit reduced or impaired zona binding, penetration, cleavage or embryo development. There are several explanations for why spermatozoa with an abnormal morphology may have low fertility. On the one hand, it has been demonstrated that most of the sperm with proximal cytoplasmic droplets are unable to swim-up [12], indicating defective motility in this type of sperm. On the other hand, the presence of cytoplasmic droplets has been related with an increase in ROS generation [40-42], which is thought to produce an alteration in the sperm membrane, decreasing fertilization capacity [43]. Furthermore, abnormal chromatin condensation has also been related to the presence of sperm abnormalities and a decrease in binding to the oviduct $[44,45]$.

As pointed out in the introduction, spermatozoa lose most of their cytoplasmatic droplets after ejaculation, while retention of them is considered a sign of infertility. Several components of the seminal fluid (e.g., hemolytic phospholipid binding protein [PBP] or fructose) has been identified as being involved in this droplet shedding [46-48], but whether the UF components would cause loss of spermatozoa droplets has not been studied. In the present study, ejaculated spermatozoa were incubated for $24 \mathrm{~h}$ in UF to mimic the environment that sperm encounter within the uterus. The results showed no relation between the presence of UF and a reduction in ejaculated sperm without cytoplasmatic droplets at different times ( 2 and $24 \mathrm{~h}$ ). Approximately $25 \%$ of the sperm used in experiment 2 (Fig. 4) had a cytoplasmic droplet even after ejaculation and UF incubation. During epididymal transit, spermatozoa are loaded with osmolytes, which are important at the time of ejaculation when the sperm are subjected to a lower osmolality than in the cauda epididymis [9], and the osmolytes are lost together with the cytoplasmic droplet due to the volume regulating mechanisms that sperm possess. The difficulty that some spermatozoa within an ejaculate have in releasing droplets could be related to an impaired volume regulatory mechanism or a poor sperm osmolyte load. As a consequence, droplets may swell, inducing a flagellar angulation that would be a disadvantage for loss of the droplet [9].

However, when epididymal spermatozoa were incubated with UF, a significant decrease in DCD was observed from $2 \mathrm{~h}$ onwards, the highest rate being observed at $24 \mathrm{~h}$. Nevertheless, when motility parameters were compared in epididymal sperm (with or without UF), no differences were found (data not shown) in any of the parameters studied by a CASA system (motility, progressive motility, VCL, VSL, VAP, LIN, STR and WOB) after $2 \mathrm{~h}$ of incubation. These results suggest that there is no relation between shedding of the distal cytoplasmic droplet in the presence of UF and an increase in motion parameters, at least under our experimental conditions.

Overall, these results indicate a role for UF in DCD removal, similar to the role played by seminal plasma. Previously, it was hypothesized [9] that epididymal spermatozoa with retained droplets, would lose their droplets when inseminated into the uterus, as occurs in ejaculated spermatozoa transferred into hypotonic inseminating medium. However, that theory does not really explain the results shown here in relation to the shedding of droplets. Since the osmolalities 
measured in the experimental groups were similar [control group (sperm without UF + PBS), 264 mOsm; and UF group (sperm with UF + PBS), $271.5 \mathrm{mOsm}$ (data not included in results)], it seems more likely that factors in the UF are involved in this process, as occurs with seminal plasma. Both uterine and oviductal fluid exhibit vesicles called exosomes that have some components, such as proteins, that contribute to modulating sperm functions. Recently, it has been shown that one of these proteins, PMCA4a, may play an important and crucial role in the regulation of $\mathrm{Ca}^{2+}$ during sperm capacitation [49], and although $\mathrm{Ca}^{2+}$ per se does not seem to be necessary for regulation of the sperm volume, the $\mathrm{Ca}^{2+}$ influx that occurs may influence it [43]. Therefore, it is possible that other proteins from the UF may modulate sperm channels, which are important for regulating cell volume and subsequent droplet shedding [50].

In the uterus, fluorescence microscopy revealed significantly higher numbers of spermatozoa at the UTJ of ewes inseminated with ejaculated sperm when compared with ewes inseminated with epididymal sperm [51], suggesting that sperm selection is somehow related to sperm morphology or maturation status. However, the results of that study indicate that epididymal sperm are able to reach the vicinity of the site where the fertilization occurs. In fact, when gilts were inseminated using epididymal sperm (from the caput, corpus and cauda segment), the rate of pregnancy ranged from 8 to $83 \%$ [52], showing that immature sperm may achieve their final maturation in contact with UF and in the absence of seminal plasma.

In conclusion, morphologically normal sperm are selected during their journey within the uterus (based on sperm characteristics and/or the influence of the female reproductive tract), and abnormal sperm are discarded in the backflow and in the uterus, ensuring an adequate population of normal sperm in the oviduct to fertilize the oocyte. The uterine horns seem to play an important role in this process, while uterine fluid components are involved in cytoplasmic droplet shedding at least in epididymal sperm.

\section{Acknowledgments}

The authors thank Juan Antonio Carvajal and Soledad Rodriguez for their technical support. This work was supported by the Spanish Ministry of Economy and Competitiveness (MINECO) and the European Regional Development Fund (FEDER) (Grant AGL2012-40180-C03-01).

\section{References}

1. Mburu JN, Einarsson S, Lundeheim N, Rodriguez-Martinez H. Distribution, number and membrane integrity of spermatozoa in the pig oviduct in relation to spontaneous ovulation. Anim Reprod Sci 1996; 45: 109-121. [Medline] [CrossRef]

2. Sumransap P, Tummaruk $\mathbf{P}$, Kunavongkrit A. Sperm distribution in the reproductive tract of sows after intrauterine insemination. Reprod Domest Anim 2007; 42: 113-117. [Medline] [CrossRef]

3. Soriano-Úbeda C, Matás C, García-Vázquez FA. An overview of swine artificial insemination: retrospective, current and prospective aspects. Journal of Experimental and Applied Animal Science 2013; 1: 67-97.

4. Holt WV, Van Look KJ. Concepts in sperm heterogeneity, sperm selection and sperm competition as biological foundations for laboratory tests of semen quality. Reproduction 2004; 127: 527-535. [Medline] [CrossRef]

5. Holt WV. Is semen analysis useful to predict the odds that the sperm will meet the egg? Reprod Domest Anim 2009; 44(Suppl 3): 31-38. [Medline] [CrossRef]

6. Kawano N, Araki N, Yoshida K, Hibino T, Ohnami N, Makino M, Kanai S, Hasuwa
H, Yoshida M, Miyado K, Umezawa A. Seminal vesicle protein SVS2 is required for sperm survival in the uterus. Proc Natl Acad Sci USA 2014; 111: 4145-4150. [Medline] [CrossRef]

7. First NL, Short RE, Peters JB, Stratman FW. Transport of boar spermatozoa in estrual and luteal sows. J Anim Sci 1968; 27: 1037-1040.

8. Fitzpatrick JL, Lüpold S. Sexual selection and the evolution of sperm quality. Mol Hum Reprod 2014; 20: 1180-1189. [Medline] [CrossRef]

9. Cooper TG. The epididymis, cytoplasmic droplets and male fertility. Asian J Androl 2011; 13: 130-138. [Medline] [CrossRef]

10. Waberski D, Meding S, Dirksen G, Weitze KF, Leiding C, Hahn R. Fertility of longterm-stored boar semen - influence of extender (androhep and kiev), storage time and plasma droplets in the semen. Anim Reprod Sci 1994; 36: 145-151. [CrossRef]

11. Althouse GC. Biochemical composition of the spermatozoal plasma membrane in normal and heat Stressed boars [thesis]. Ames: Iowa State University; 1992.

12. Amann RP, Seidel GE Jr, Mortimer RG. Fertilizing potential in vitro of semen from young beef bulls containing a high or low percentage of sperm with a proximal droplet. Theriogenology 2000; 54: 1499-1515. [Medline] [CrossRef]

13. Thundathil J, Palasz AT, Barth AD, Mapletoft RJ. The use of in vitro fertilization techniques to investigate the fertilizing ability of bovine sperm with proximal cytoplasmic droplets. Anim Reprod Sci 2001; 65: 181-192. [Medline] [CrossRef]

14. Peña AI, Barrio M, Becerra JJ, Quintela LA, Herradón PG. Infertility in a dog due to proximal cytoplasmic droplets in the ejaculate: investigation of the significance for sperm functionality in vitro. Reprod Domest Anim 2007; 42: 471-478. [Medline] [CrossRef]

15. Althouse GC. Cytoplasmic droplets on boar sperm cells. Swine. Health Prog 1998; 6 : 128.

16. Petrunkina AM, Gehlhaar R, Drommer W, Waberski D, Töpfer-Petersen E. Selective sperm binding to pig oviductal epithelium in vitro. Reproduction 2001; 121: 889-896. [Medline] [CrossRef]

17. Merton H. Studies on reproduction in the albino mouse. II. Contributions on the maturation of the sperm cells. Proc Roy Soc 1939; 59: 145-152. (Edinburgh).

18. Mortimer D, Leslie EE, Kelly RW, Templeton AA. Morphological selection of human spermatozoa in vivo and in vitro. J Reprod Fertil 1982; 64: 391-399. [Medline] [CrossRef]

19. Pretorius E, Franken DR, De Wet J, Grobler S. Sperm selection capacity of cervical mucus. Arch Androl 1984; 12: 5-7. [Medline] [CrossRef]

20. García-Vázquez FA, Ruiz S, Matás C, Izquierdo-Rico MJ, Grullón LA, De Ondiz A, Vieira L, Avilés-López K, Gutiérrez-Adán A, Gadea J. Production of transgenic piglets using ICSI-sperm-mediated gene transfer in combination with recombinase RecA. Reproduction 2010; 140: 259-272. [Medline] [CrossRef]

21. Matás C, Sansegundo M, Ruiz S, García-Vázquez FA, Gadea J, Romar R, Coy P. Sperm treatment affects capacitation parameters and penetration ability of ejaculated and epididymal boar spermatozoa. Theriogenology 2010; 74: 1327-1340. [Medline] [CrossRef]

22. Hafez ESE, Hafez B. Folliculogenesis, egg maturation, and ovulation. Reproduction in Farm Animals 2000: 68-81.

23. Carrasco LC, Romar R, Avilés M, Gadea J, Coy P. Determination of glycosidase activity in porcine oviductal fluid at the different phases of the estrous cycle. Reproduction 2008; 136: 833-842. [Medline] [CrossRef]

24. Gadea J, Sellés E, Marco MA. The predictive value of porcine seminal parameters on fertility outcome under commercial conditions. Reprod Domest Anim 2004; 39: 303-308. [Medline] [CrossRef]

25. Viring S, Einarsson S. Sperm distribution within the genital tract of naturally inseminated gilts. Nord Vet Med 1981; 33: 145-149. [Medline]

26. Steverink DW, Soede NM, Bouwman EG, Kemp B. Semen backflow after insemination and its effect on fertilisation results in sows. Anim Reprod Sci 1998; 54: 109-119. [Medline] [CrossRef]

27. Mezalira A, Dallanora D, Bernardi M, Wentz I, Bortolozzo FP. Influence of sperm cell dose and post-insemination backflow on reproductive performance of intrauterine inseminated sows. Reprod Domest Anim 2005; 40: 1-5. [Medline] [CrossRef]

28. Hernández-Caravaca I, Soriano-Úbeda C, Matás C, Izquierdo-Rico MJ, GarcíaVázquez FA. Boar sperm with defective motility are discriminated in the backflow moments after insemination. Theriogenology 2015; 83: 655-661. [Medline] [CrossRef]

29. Hernández-Caravaca I, Izquierdo-Rico MJ, Matás C, Carvajal JA, Vieira L, Abril D, Soriano-Úbeda C, García-Vázquez FA. Reproductive performance and backflow study in cervical and post-cervical artificial insemination in sows. Anim Reprod Sci 2012; 136: 14-22. [Medline] [CrossRef]

30. Hunter RHF. The Fallopian Tubes: Their Role in Fertility and Infertility. Springer-Verlag, Berlin, Heidelberg, New York. 1988.

31. Holt WV, Fazeli A. Do sperm possess a molecular passport? Mechanistic insights into sperm selection in the female reproductive tract. Mol Hum Reprod 2015; 21: 491-501. [Medline] [CrossRef]

32. Kasimanickam R, Nebel RL, Peeler ID, Silvia WL, Wolf KT, McAllister AJ, Cas- 
sell BG. Breed differences in competitive indices of Holstein and Jersey bulls and their association with sperm DNA fragmentation index and plasma membrane integrity. Theriogenology 2006; 66: 1307-1315. [Medline] [CrossRef]

33. Mangiarini A, Paffoni A, Restelli L, Ferrari S, Guarneri C, Ragni G, Somigliana E. Specific sperm defects are differentially correlated with DNA fragmentation in both normozoospermic and teratozoospermic subjects. Andrology 2013; 1: 838-844. [Medline] [CrossRef]

34. Vogelpoel FR, Verhoef J. Activation of polymorphonuclear leukocytes by spermatozoa. Arch Androl 1985; 14: 123-131. [Medline] [CrossRef]

35. Eisenbach M. Why are sperm cells phagocytosed by leukocytes in the female genital tract? Med Hypotheses 2003; 60: 590-592. [Medline] [CrossRef]

36. Matthijs A, Engel B, Woelders H. Neutrophil recruitment and phagocytosis of boar spermatozoa after artificial insemination of sows, and the effects of inseminate volume, sperm dose and specific additives in the extender. Reproduction 2003; 125: 357-367. [Medline] [CrossRef]

37. Taylor U, Rath D, Zerbe H, Schuberth HJ. Interaction of intact porcine spermatozoa with epithelial cells and neutrophilic granulocytes during uterine passage. Reprod Domest Anim 2008; 43: 166-175. [Medline] [CrossRef]

38. Yeste M, Castillo-Martín M, Bonet S, Briz MD. Direct binding of boar ejaculate and epididymal spermatozoa to porcine epididymal epithelial cells is also needed to maintain sperm survival in in vitro co-culture. Anim Reprod Sci 2012; 131: 181-193. [Medline] [CrossRef]

39. Liu DY, Baker HW. Morphology of spermatozoa bound to the zona pellucida of human oocytes that failed to fertilize in vitro. $J$ Reprod Fertil 1992; 94: 71-84. [Medline] [CrossRef]

40. Gomez E, Buckingham DW, Brindle J, Lanzafame F, Irvine DS, Aitken RJ. Development of an image analysis system to monitor the retention of residual cytoplasm by human spermatozoa: correlation with biochemical markers of the cytoplasmic space, oxidative stress, and sperm function. $J$ Androl 1996; 17: 276-287. [Medline]

41. Aziz N, Saleh RA, Sharma RK, Lewis-Jones I, Esfandiari N, Thomas AJ Jr, Agarwal A. Novel association between sperm reactive oxygen species production, sperm morphological defects, and the sperm deformity index. Fertil Steril 2004; 81: 349-354. [Medline]
[CrossRef]

42. Said TM, Agarwal A, Sharma RK, Thomas AJ Jr, Sikka SC. Impact of sperm morphology on DNA damage caused by oxidative stress induced by beta-nicotinamide adenine dinucleotide phosphate. Fertil Steril 2005; 83: 95-103. [Medline] [CrossRef]

43. Aitken RJ, Gordon E, Harkiss D, Twigg JP, Milne P, Jennings Z, Irvine DS. Relative impact of oxidative stress on the functional competence and genomic integrity of human spermatozoa. Biol Reprod 1998; 59: 1037-1046. [Medline] [CrossRef]

44. Dadoune JP, Mayaux MJ, Guihard-Moscato ML. Correlation between defects in chromatin condensation of human spermatozoa stained by aniline blue and semen characteristics. Andrologia 1988; 20: 211-217. [Medline] [CrossRef]

45. Ardón F, Helms D, Sahin E, Bollwein H, Töpfer-Petersen E, Waberski D. Chromatinunstable boar spermatozoa have little chance of reaching oocytes in vivo. Reproduction 2008; 135: 461-470. [Medline] [CrossRef]

46. Matousek J, Kysilka C. The hemolytic factor (phospholipid-binding protein) of the bull reproductive-tract - its synthesis and effect on spermatozoal cytoplasm droplets. Anim Reprod Sci 1980; 3: 195-205. [CrossRef]

47. Matousek J, Kysilka $\mathbf{C}$. The phospholipid-binding protein of the reproductive-tract of the bull - effect on the removal of spermatozoal cytoplasm droplets in other species an influence of antibodies on its reactivity. Anim Reprod Sci 1984; 7: 433-440. [CrossRef]

48. Harayama H, Shibukawa T, Miyake M, Kannan Y, Kato S. Fructose stimulates shedding of cytoplasmic droplets from epididymal boar spermatozoa. Reprod Fertil Dev 1996 8: 1039-1043. [Medline] [CrossRef]

49. Al-Dossary AA, Strehler EE, Martin-Deleon PA. Expression and secretion of plasma membrane $\mathrm{Ca}^{2+}$-ATPase 4a (PMCA4a) during murine estrus: association with oviductal exosomes and uptake in sperm. PLoS ONE 2013; 8: e80181. [Medline] [CrossRef]

50. Yeung CH, Barfield JP, Cooper TG. Physiological volume regulation by spermatozoa. Mol Cell Endocrinol 2006; 250: 98-105. [Medline] [CrossRef]

51. Rickard JP, Pini T, Soleilhavoup C, Cognie J, Bathgate R, Lynch GW, Evans G, Maxwell WM, Druart X, de Graaf SP. Seminal plasma aids the survival and cervical transit of epididymal ram spermatozoa. Reproduction 2014; 148: 469-478. [Medline] [CrossRef]

52. Holtz W, Smidt D. The fertilizing capacity of epididymal spermatozoa in the pig. $J$ Reprod Fertil 1976; 46: 227-229. [Medline] [CrossRef] 